\title{
Charles Sorel, Description de l'île de portraiture
}

\section{Laura Rescia}

\section{(2) OpenEdition}

\section{Journals}

\section{Edizione digitale}

URL: http://journals.openedition.org/studifrancesi/9190

DOI: 10.4000/studifrancesi.9190

ISSN: 2427-5856

\section{Editore}

Rosenberg \& Sellier

\section{Edizione cartacea}

Data di pubblicazione: 1 juin 2008

Paginazione: 179-180

ISSN: 0039-2944

\section{Notizia bibliografica digitale}

Laura Rescia, «Charles Sorel, Description de l'̂̂le de portraiture», Studi Francesi [Online], 154 (LII | I) | 2008 , online dal 30 novembre 2015, consultato il 11 janvier 2021. URL: http://journals.openedition.org/ studifrancesi/9190 ; DOI: https://doi.org/10.4000/studifrancesi.9190

Questo documento è stato generato automaticamente il 11 janvier 2021.

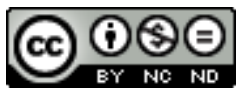

Studi Francesi è distribuita con Licenza Creative Commons Attribuzione - Non commerciale - Non opere derivate 4.0 Internazionale. 


\title{
Charles Sorel, Description de l'île de portraiture
}

\author{
Laura Rescia
}

\section{NOTIZIA}

CHARLES SOREL, Description de l'île de portraiture, éd. critique par M. DEBAISIEUX, préface par M. JEANNERET, Genève, Droz, 2006, pp. 199.

1 Le opere di Charles Sorel conoscono attualmente una nuova stagione di riedizioni: Honoré Champion ha stampato nel 2005 Les Nouvelles Choisies (a cura di D. Dalla Valle), mentre sono in preparazione Le Berger Extravagant, Polyandre e La Bibliothèque Françoise. Anche Droz ha voluto inserirsi in questa nouvelle vague, pubblicando nella collana «Textes littéraires français» un testo esemplarmente soreliano per diversi aspetti. Apparsa a Parigi per i tipi di Sercy nel 1659, e situata nel secondo periodo dell'autore, quando egli abbandona la scrittura di divertissement, La description è una narrazione che sfugge ai tentativi di definizione di genere, come l'editrice moderna sottolinea nella ricca introduzione. Se nella Bibliothèque Françoise Sorel classifica questa sua opera sotto la rubrica 'des fables et des allegories', è pur vero che essa si configura come viaggio immaginario, ereditando alcuni tratti del genere utopico (presenza di un mentore, governo ideale) ma avvicinandosi altresì alla cartografia galante. Tale configurazione ibridata si innesta inoltre sulla tradizione satirica: qui Sorel si scaglia contro la moda del ritratto letterario, inauguratosi con Mlle de Montpensier e i suoi Divers portraits nel 1659. La tematica del ritratto attraversa peraltro tutta la produzione soreliana, non soltanto a fini satirici, in quanto costituisce spesso l'occasione per una riflessione sul tema della rappresentazione e sulla dialettica tra realtà e illusione. Con una pratica paradossale che è la sua cifra caratterizzante, Sorel utilizza gli stilemi del genere che intende criticare: nell'Anti-roman quelli romanzeschi, in questo caso la finzione allegorica. 
2 L'edizione di Martine Debaisieux riproduce il testo originale, con ortografia e punteggiatura modernizzate, nonché con qualche variante tipografica al servizio del lettore moderno; particolarmente apprezzabile, un dossier complementare antologizza la presenza del ritratto nei romanzi di Sorel, e la moda del ritratto letterario nella letteratura coeva. La prefazione di Michel Jeanneret contestualizza l'opera e propone una riflessione sulla rappresentazione del corpo nel XVII secolo tra censura moralizzante ed esibizione carnevalesca. 